\title{
A Newly Proposed HIS Implementation Success Model for Nursing, using an Electronic Approach for Design
}

\author{
Shahab Rezaian \\ Ph.D. candidate of \\ Information Systems \\ at Advanced \\ Informatics School \\ Universiti \\ Teknologaysia, \\ JalanSemarak, KL, \\ Malaysia, 54100
}

\author{
Harhodin Bin \\ Selamat \\ Ph.D., Associate \\ Professor at \\ Advanced \\ Informatics School, \\ Universiti Teknologi \\ Malaysia, \\ jalanSemarak, KL, \\ Malaysia, 54100
}

\author{
Reza \\ Malekzadeh \\ MD.Professor of \\ Medicine, Digestive \\ Disease Research \\ Institute, Tehran \\ University of Medical \\ Sciences, Shariati \\ Hospital, \\ Tehran, Iran
}

\author{
Rasimah \\ CheMohd Yusoff \\ Ph.D.Lecturer at \\ Advanced \\ Informatics School, \\ UniversitiTeknologi \\ Malaysia, \\ JalanSemarak, KL, \\ Malaysia, 54100
}

\begin{abstract}
Despite the advantages of utilizing hospital information systems (HISs) in nursing care, and their contribution to nursing structures and care processes, the troubling issue of HIS underutilization continues. Low utilization of installed systems has been identified as a major problem in implementing information technology (IT). Unfortunately, nurses have been unwilling to apply technology to healthcare delivery, although they generally have a positive attitude toward computers. In this study, based on the Critical Success Factos (CSFs) and DeLone and McLean's Information Systems success model, an implementation framework, made up of essential elements to guide successful HIS implementation for nursing staff is proposed. This study is among the few that have tested empirically an implementation framework in the developing countries settings, and provides helpful guidelines for hospital managers in planning HIs implementation in such countries.
\end{abstract}

\section{General Terms}

Critical success factors, Hospital Information System, Success model, DeLone and McLean.

\section{Keywords}

Hospital Information System, Success model, Information culture, Organization culture, trust, developing countries.

\section{INTRODUCTION}

Information systems (IS) are used by organizations to store, filter and process data (Wikipedia). Hospitals are investing a large amount of money on HIS to get benefits from these systems. Since large investments are made in IT, the organizations are interested in knowing the success of these systems and want to find out the impact of these systems on them as well as on individuals.[1] The effectiveness of these systems depends upon many factors like organizational, environmental and people who use them [2]. It is not easy to evaluate the success of information systems so measuring IS success is of utmost importance. It is a multidimensional concept that can be evaluated at various levels [3].

Malik and Khan [4] have suggested that for leading successful implementation of IS in any organization there must be some change process. They have explained that the developing countries are facing problems to get benefits of IS. Overall, the success rate of HIS implementation is very low in developing countries [5-6]. There are scarce examples on successful implementation of HIS in developing countries as compared to developed countries. The studies from the developed countries can't be utilized as guideline for the implementation process in developing countries because in both, the working culture and circumstances are different. Therefore a new model is designed to provide a new HIS implementation framework which may include the cultural characteristics of each individual hospital and could hopefully be successfully implemented in the health organizations of the region.

\section{REVIEW OF LITERATURE}

\subsection{HIS}

Hospital Information System (HIS) is considered as an important factor in health care sector for managing the administrative, financial and clinical aspects of a hospital. A large number of hospitals from both developing and developed countries are adopting hospital information system to bring efficiency in their current system [7].

During the last few decades health care managers have tried to maximize hospitals' productivity, without reducing the quality of health care services provided to the patients [8-10].

Recent literature suggests that the adoption of Health information system in hospitals can improve information and service integration, communication, and coordination among clinicians [11-14], health care quality and safety [15], reduce costs [16], control resource allocation, increase service efficiency and productivity, and enhance service availability, quality, and satisfaction for patients and health care providers [17-19]. HIS may also improve health care quality through the use of standardized clinical pathways; e-prescribing systems, which would detect drug interactions; and better and more complete documentation of care [14]. These improved processes are expected to lead to significant reductions in medical errors [20-21]. The automated access of physicians to patient laboratory and other diagnostic results may reduce lost orders and errors due to illegible handwriting, and minimize duplicate orders [22], thus improving health care quality outcomes and efficiency [23]. Patient satisfaction as an outcome indicator of health care delivery has been widely accepted as a significant indicator for measuring quality of health care and as a critical component in performance improvement and clinical effectiveness [11, 24-25]. 
The ability of hospitals to effectively utilize the required information systems is of the greatest concern. Hospitals implemented HISs to improve the efficiency and effectiveness of their healthcare professionals [26], as well as to meet requirements for high-quality patient care. HIS tries to bring together the clinical and administrative functions of a hospital. This system has become an essential tool in many healthcare systems, used in acquiring, processing and managing the patient's abundant and complex information during their stay in the hospital, or even for outpatient visits, and it supports all the practical, tactical and strategic hospital activities [27].

\subsection{HIS and the nursing staff.}

In the field of nursing, as the amount and nature of the information necessary has become more complex, HISs have been introduced to support nurses' daily activities [28]. Using HIS in the daily activities of nursing has become a prerequisite. However, the use of an HIS can be quite diverse in these activities. For instance, practicing nurses, who work in the front-line of care and handle a large portion of the patient information, use an HIS more than ward managers or nursing directors who are involved in nursing management.

HISs are gradually being integrated more efficiently into nursing care, and they offer important benefits to healthcare, including the possibility of real time access, with the exchange and receiving of clinical data. Generally, information processing in a hospital is affected by HISs [28]. The effect has been to improve clinical documentation and to reduce the duplication of care services, thereby improving the quality of patient care and enhancing decision making [29]. Although the improvement of clinical documentation supports the process of nursing care, and helps hospitals to improve the efficiency of the healthcare facilities, the most challenging issue in the context of nursing care is the effect of using HISs on the time available for patient care [30-31]. Use of HISs creates an opportunity for nurses to reduce their daily time requirement for all the activities involved in manually creating medical records, such as vital signs, laboratory results and ordering prescriptions [30], charting times, as well as nursing overtime. Thus, nursing care delivery is facilitated as more time can be allocated to direct patient care [32]. In addition, the use of HIS enables nurses to record data quickly, and to represent nursing interventions with little effort and high quality [33]. HIS has the potential to facilitate nursing care delivery by the reduction of documentation time, increasing the time available for patient care tasks and patient assessment [32]. Thus, the time saved on documentation can be utilized by nurses in their care and assessment, thereby the whole patient care process, involving planning, coordination and organizing of nursing care, can be improved [34].

Since the nursing process embraces recognition of patient's requirements, the responses of nurses and their nursing actions require ready access to timely, up to date, complete and relevant information [35] if they are to get a complete picture of their patients' conditions, thereby enabling them to follow all the steps of the nursing process. If quality nursing care is to be provided it is essential that this requirement is met. It must be remembered that in practice nurses deal with huge volumes of patients' information during a shift, and nursing care has become an information intensive area; HIS has increasingly become an appropriate tool for the addressing of nurses' needs in processing patient information [36].

Nurses can better appreciate the advantages of technology if they accept and integrate these technologies into their daily work [37]. Hence, the involvement of nurses in the use of HIS is the most important factor affecting its use, and acceptance of IT is a constant issue [38]. Acceptance of HIS by the largest element within the healthcare system [39] would allow healthcare organizations to significantly enhance the delivery of care.

Despite the advantages of utilizing HISs in nursing care, and their contribution to nursing structures and care processes, the troubling issue of HIS underutilization continues. Low utilization of installed systems has been identified as a major problem in implementing IT [40-41]. Unfortunately, nurses have been unwilling to apply technology to healthcare delivery [42], although they generally have a positive attitude toward computers [43-44].

\section{MATERIAL AND METHODS}

Several steps were taken to develop this proposed HIS implementation success model.

\subsection{Literature review}

A thorough literature review was performed to find out the most popular technology acceptance theories and information system (IS) success models. Six prominent intention-based theories were identified which included: The Theory of Reasoned Action (TRA) [45], Technology Acceptance Models (TAM) [46] and TAM2 [47], Theory of Planned Behavior (TPB) [48], Combined TAM and TPB (C-TAM-TPM) [49] and the Unified Theory of Acceptance and Use of Technology (UTAUT) [47]. The common factor among these theories is to explain the behavioral usage of information technology [50].

Of the success models presented in the literature, the updated DeLone and McLean's [3] IS success model (Figure 1) appeared to be the most popular and frequently-cited one. This model is helpful to formulate and build up the success model as well.

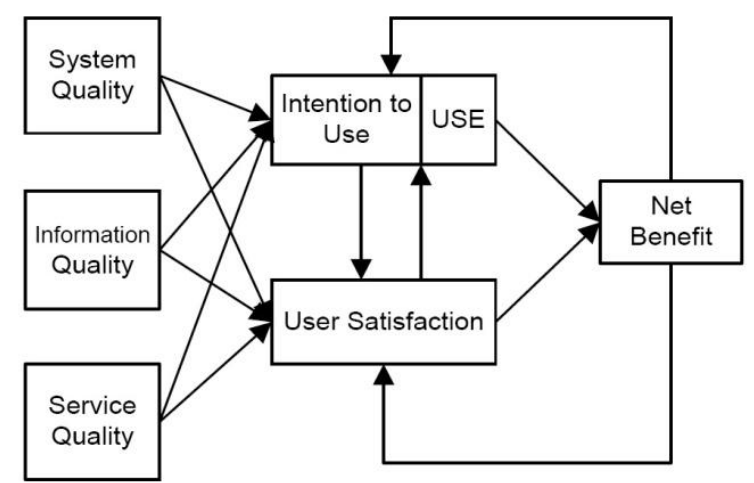

Figure 1: The DeLone and McLean Updated IS success model (adopted from DeLone and McLean, 2003)

\subsection{Critical success model}

Since to ensure continuous successful implementation, the understanding and determination of important critical success factors and elements are essential, the literature was reviewed specifically in this regard too. The most common implemented constructs and measures were extracted and were used to make the questionnaire for the interview with the expert panel.

\subsection{The expert panel}

To find out an appropriate expert panel for interview, the available literature and journal articles about successful HIS implementation were gathered and the emails of their main authors (first and/or corresponding) were collected and used for the subsequent electronic contact. As such one hundred authors 
from all-over the world were collected and considered to be expert panel in this research.

\subsection{The instrument}

The questionnaire consisting of ten main constructs and multiple relevant measures was electronically mailed to all of the one hundred authorities with a letter describing the purpose of the investigation and asking their kind participation and prompt answer. The questionnaire was designed to get the viewpoints of experts regarding the major constructs affecting the success of HIS implementation. A Likert scale was used (Table 1). Experts were asked to score each item from 1 to 7 based on their perception regarding the significance of any particular parameter. A score of " 0 " was considered as "no answer".

Table 1: Showing the 7-point Likert response scale for assessment of the expert views on the effectiveness of the constructs and their measures on the successful HIS implementation

\begin{tabular}{|c|c|c|c|c|c|c|c|c|}
\hline \multirow[b]{2}{*}{ 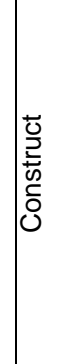 } & \multirow[b]{2}{*}{ 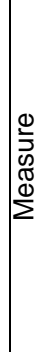 } & \multicolumn{7}{|c|}{ Effect on successful HIS implementation } \\
\hline & & 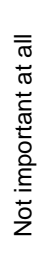 & 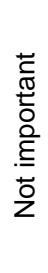 & 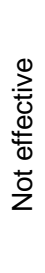 & 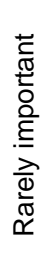 & 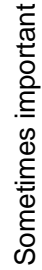 & 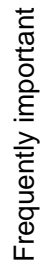 & 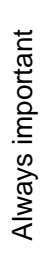 \\
\hline
\end{tabular}

\subsection{The content validity index}

The content validity index for scales (S-CVI) [51] was used to assess the experts' responses regarding the relevance of each item (measure) with the appropriate construct being evaluated. As stated by Polit and Beck [52], content validity index can be defined as "... the degree to which an instrument has an appropriate sample of items for the construct being measured". Actually content validity is concerned with the degree to which a group of items, taken together, constitute an adequate operational definition of a given construct. A SCVI $\geq 0.8$ was considered acceptable [53].

\section{RESULTS}

Overall 21 experts responded back via email. Of the 10 constructs, 9 were approved and 1, the social influence, was rejected (Table 2). But the newly added constructs, the information culture, the organization culture as well as trust and user quality were strongly selected (Table 2).

Figure 2 shows the graphic demonstration of the expert's responses regarding the information quality construct.

Putting all available selected and validated constructs, dimensions and parameters the following HIS success model was proposed (Figure 3).

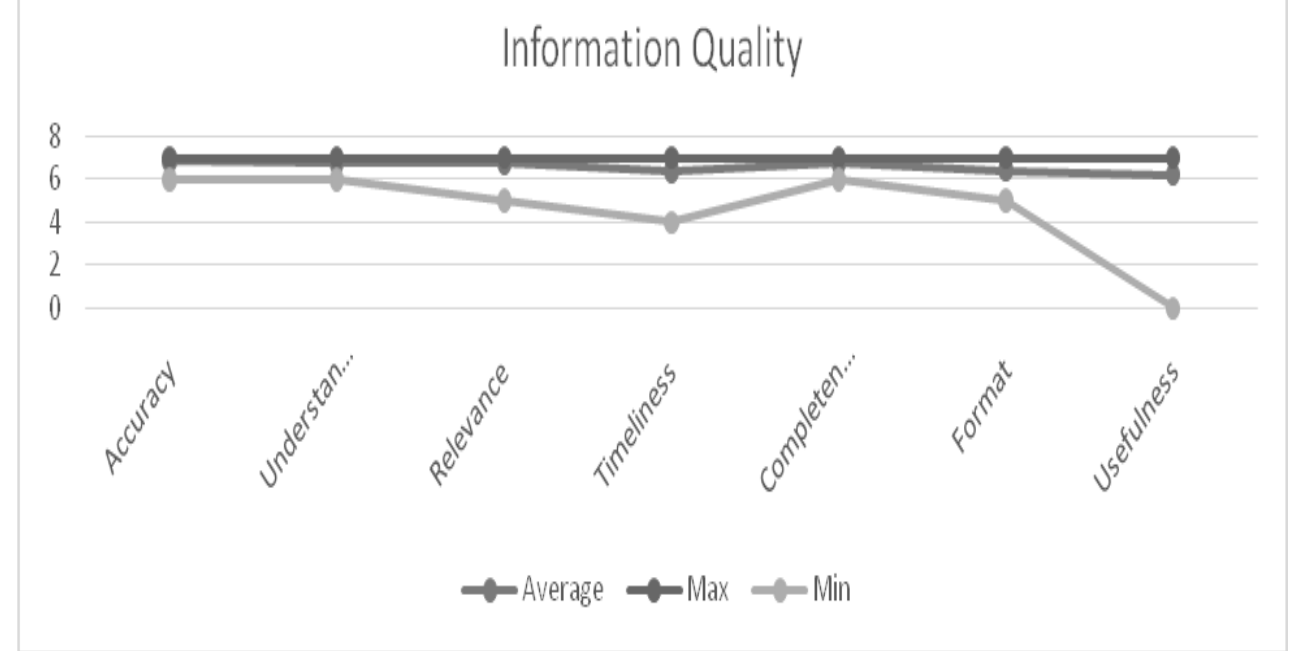

Figure 2: Showing the maximum, minimum and average scores of measures regarding the information quality construct

Table 2: The scale content validity index (S-CVI) of the ten constructs used for the proposed HIS success model

\begin{tabular}{|l|c|c|c|}
\hline \multicolumn{1}{|c|}{ Construct } & S-CVI/AVE & Accepted & Rejected \\
\hline User Quality & 0.80 & $\sqrt{ }$ & \\
\hline System Quality & 0.96 & $\sqrt{ }$ & \\
\hline Information Quality & 0.94 & $\sqrt{ }$ & \\
\hline Service Quality & 0.89 & $\sqrt{ }$ & \\
\hline
\end{tabular}




\begin{tabular}{|l|c|c|c|}
\hline Intention to use/ Use & 0.92 & $\sqrt{ }$ & \\
\hline Trust & 1.00 & $\sqrt{ }$ & \\
\hline Social influence & 0.77 & & $\sqrt{ }$ \\
\hline $\begin{array}{l}\text { Culture (information and } \\
\text { organization) }\end{array}$ & 0.83 & $\sqrt{ }$ & \\
\hline User satisfaction & 0.88 & $\sqrt{ }$ & \\
\hline Net Benefit & 0.88 & $\sqrt{ }$ & \\
\hline
\end{tabular}

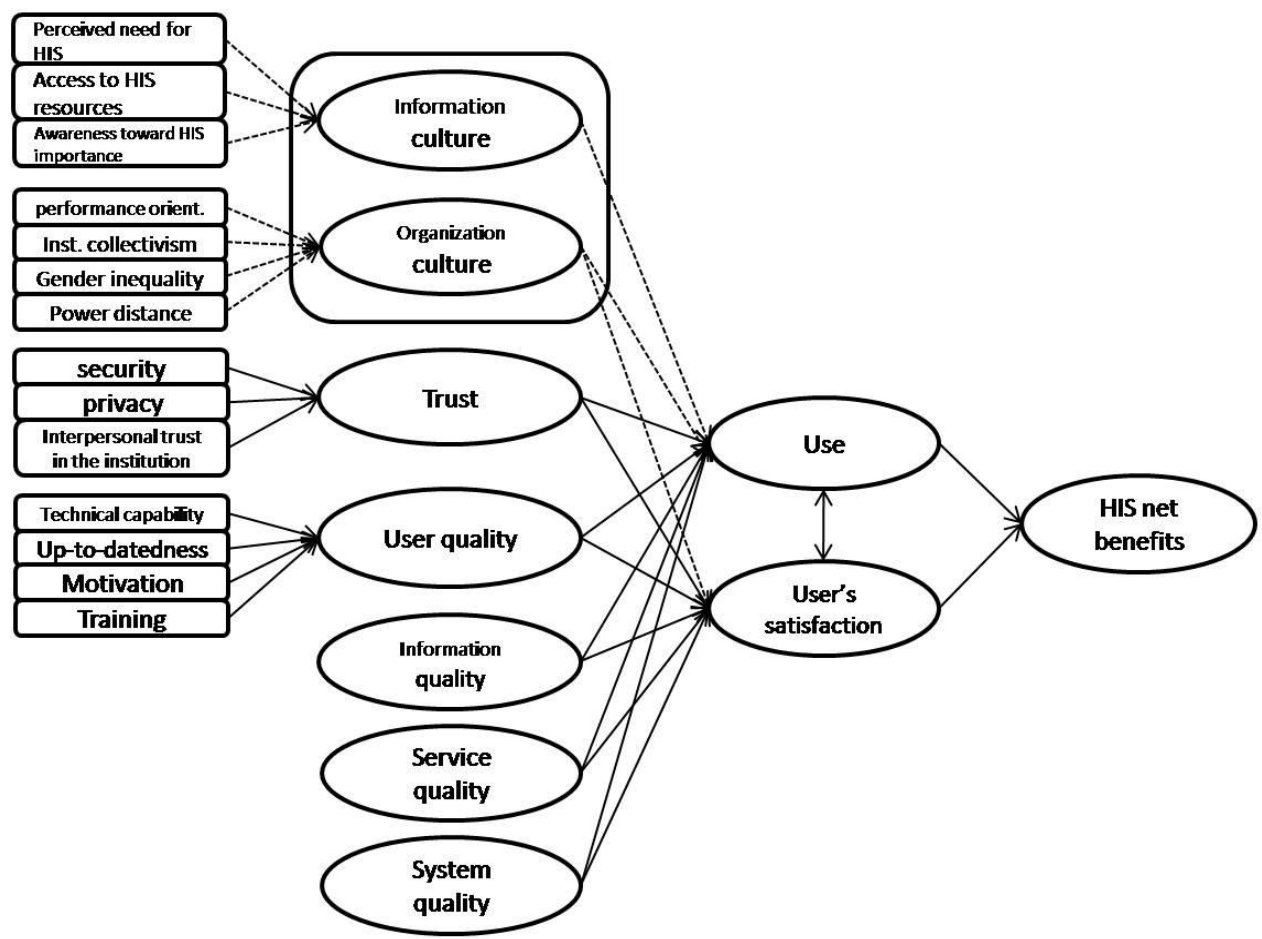

Inst.: Institution, Orient.: Orientation

Figure 3: showing the newly proposed HIS implementation success model

\section{DISCUSSION}

A new HIS implementation success model basically derived from the constructs and success items selected and approved by a group of 21 experts. The DeLone and McLean's IS success model constitute the major body and framework of new model.

Since the DeLone and McLean's model can provide a good framework to identify and develop different measures for several important dimensions, it could also be used in the field of human-centered technology to understand different aspects of IS success. Both the original and updated models have been based on literature reviews and many researchers have tried to validate, use and develop these models further. However, instead of having ready-to-use measures, there is a lot of work to be done when modifying the model for own purposes, and this is what has been done in the present work too.
Health care systems are investing a large amount of money on HIS and are interested in knowing the success or failure of these systems. Therefore, the benefits of the HISs require frequent and rigorous evaluation. It is said that organizational and social issues are the main components of such a system [54]. The more technology, human and organization fit with each other, the greater would be the productivity of HIS. Most existing evaluation studies of HIS focus on technical issues or clinical processes, which do not explain why HIS works well or poorly with a specific user in a specific setting [55]. Hence it becomes important as well as necessary to develop and present various IS success models.

Baus [56] explains that in some cases the organizational nature of HIS implementation is more important than its technical components. HIS can modify the working relationships between the people working in the hospital and 
it has positive effect on the ways in which hospital staff work together provide health care, and carry out their daily work practices. According to Wager et al. [57] the impact on the organizational structure must be understood before the successful implementation of HIS.

Since the HIS assists healthcare providers to streamline the flow of patients' information and its accessibility, the significance of the HIS in providing high quality patient care has grown [58]. Therefore, implementation of HIS becomes fundamentally essential in meeting associated diagnostic, treatment and administration requirements, and thereby in delivering better patient care and support to clinical decision making [59]. The HIS has clearly led to a change in the process of care delivery, and has helped to improve the quality and safety of care [29, 58, 60-62]. However, compared to other technologies in the healthcare domain, the acceptance level of HIS is still low [63-64].

An IS may fail or it can be successfully implemented in any environment. In both developing and developed countries, the research contains success and failure issues [65]. Human and financial barriers have been found to be two major categories of barriers challenging in the way of successful HIS implementation in the developing countries [66].

Other than selecting a research [67] topic and an appropriate research design, research method is considered to be another major component since it specifies the forms of data collection, analysis and interpretation [67]. The forms of data collection are questionnaires, interviews and observations. The choice of methods is largely governed by the purpose of the study, time constraints, available budget and resources, so that the method's bias can be addressed [68-69].

According to Ridder [70], data collection for qualitative research include many ways like reviewing documents, archival records, interviews, direct observation and participant observation. Interviews are used to get deep understanding of participant's views and ideas regarding the research questions. As Creswell [67] stated, by conducting interviews, most relevant and accurate data could be collected for research purposes. Interviews can be conducted as face to face interaction, online interaction, email interaction, or phone interaction.

As the number of the critical success factors and measures to develop the proposed success model as well as the number of the experts were too many, the electronic mail method was used since it needed only a one time set up, and was much cheaper and faster than other data collection methods.

\section{CONCLUSION}

Here a new HIS implementation success model has been proposed for the nursing staffs of hospitals in the developing countries. It is clear that because of cultural and economical differences the model from developed countries can't be utilized as proper guidelines for HIS implementation in developing countries. Therefore, it is hoped that this model would help the successful implementation of HIS in the health care organizations of the region.

\section{REFERENCES}

[1] Gable, G., Sedera, D., and Chan, T. 2003. Enterprise systems success: a measurement model. ICIS 2003 Proceedings. 48.

[2] Petter, S., DeLone, W., and McLean, E. 2008. Measuring information systems success: models, dimensions, measures, and interrelationships. European journal of information systems. 17 236-263.

[3] Delone, W. H. and McLean, E. R. 2003. The DeLone and McLean model of information systems success: a ten-year update. Journal of management information systems. 19 9-30.

[4] Malik, M. A. and Khan, H. R. 2009. Understanding the implementation of an electronic hospital information system in a developing country: a case study from Pakistan. Proceedings of the Third Australasian Workshop on Health Informatics and Knowledge Management-Volume 97.

[5] ALTUWAIJRI, M. 2012. Health Information Technology Strategic Planning Alignment in Saudi Hospitals: A Historical Perspective. Journal of Health Informatics in Developing Countries. 5

[6] Khalifa, M. 2014. Technical and Human Challenges of Implementing Hospital Information Systems in Saudi Arabia. Journal of Health Informatics in Developing Countries. 8

[7] Cimino, J. J. and Shortliffe, E. H. 2006 Biomedical Informatics: Computer Applications in Health Care and Biomedicine (Health Informatics). Springer-Verlag New York, Inc.

[8] Escobar-Rodríguez, T. and Bartual-Sopena, L. 2014. Impact of cultural factors on attitude toward using ERP systems in public hospitals. Revista de Contabilidad.

[9] Herwartz, H. and Strumann, C. 2014. Hospital efficiency under prospective reimbursement schemes: an empirical assessment for the case of Germany. The European Journal of Health Economics. 15 175-186.

[10] Pizzini, M. J. 2006. The relation between cost-system design, managers' evaluations of the relevance and usefulness of cost data, and financial performance: an empirical study of US hospitals. Accounting, Organizations and Society. 31 179-210.

[11] Roham, M., Gabrielyan, A. R., and Archer, N. P. 2012. Predicting the impact of hospital health information technology adoption on patient satisfaction. Artificial intelligence in medicine. 56 123-135.

[12] Tabibi, S. J., Nasiripour, A. A., Kazemzadeh, R. B., Farhangi, A. A., and Ebrahimi, P. 2011. Effective Factors on Hospital Information System Acceptance: A Confirmatory Study in Iranian Hospitals. Middle-East Journal of Scientific Research. 9 95-101.

[13] Brailer, D. J. 2005. Interoperability: the key to the future health care system. HEALTH AFFAIRS-MILLWOOD VA THEN BETHESDA MA-. 24 W5.

[14] Detmer, D., Bloomrosen, M., Raymond, B., and Tang, P. 2008. Integrated personal health records: transformative tools for consumer-centric care. BMC medical informatics and decision making. 845 .

[15] Epping-Jordan, J., Pruitt, S., Bengoa, R., and Wagner, E. 2004. Improving the quality of health care for chronic conditions. Quality and safety in health care. 13 299-305.

[16] Girosi, F., Meili, R. C., and Scoville, R. 2005 Extrapolating evidence of health information technology savings and costs. Rand Corporation. 
[17] Nagle, L. and Catford, P. 2007. Toward a model of successful electronic health record adoption. Healthcare quarterly (Toronto, Ont.). 11 84-91.

[18] Eslami, S., de Keizer, N. F., and Abu-Hanna, A. 2008. The impact of computerized physician medication order entry in hospitalized patients - a systematic review. International journal of medical informatics. 77 365-376.

[19] Häyrinen, K., Saranto, K., and Nykänen, P. 2008. Definition, structure, content, use and impacts of electronic health records: a review of the research literature. International journal of medical informatics. 77 291-304.

[20] Koppel, R., Metlay, J. P., Cohen, A., Abaluck, B., Localio, A. R., Kimmel, S. E., and Strom, B. L. 2005. Role of computerized physician order entry systems in facilitating medication errors. Jama. 293 1197-1203.

[21] King, W. J., Paice, N., Rangrej, J., Forestell, G. J., and Swartz, R. 2003. The effect of computerized physician order entry on medication errors and adverse drug events in pediatric inpatients. Pediatrics. 112 506-509.

[22] Reckmann, M. H., Westbrook, J. I., Koh, Y., Lo, C., and Day, R. O. 2009. Does computerized provider order entry reduce prescribing errors for hospital inpatients? A systematic review. Journal of the American Medical Informatics Association. 16 613-623.

[23] Chaudhry, B., Wang, J., Wu, S., Maglione, M., Mojica, W., Roth, E., Morton, S. C., and Shekelle, P. G. 2006. Systematic review: impact of health information technology on quality, efficiency, and costs of medical care. Annals of internal medicine. 144 742-752.

[24] Messner, E. R. 2005. Quality of care and patient satisfaction: The improvement efforts of one emergency department. Advanced Emergency Nursing Journal. 27 132-141.

[25] Young, G. J., Meterko, M., and Desai, K. R. 2000. Patient satisfaction with hospital care: effects of demographic and institutional characteristics. Medical care. 38 325-334.

[26] Hung, S.-Y., Ku, Y.-C., and Chien, J.-C. 2012. Understanding physicians' acceptance of the Medline system for practicing evidence-based medicine: a decomposed TPB model. International Journal of Medical Informatics. 81 130-142.

[27] Ammenwerth, E., Rauchegger, F., Ehlers, F., Hirsch, B., and Schaubmayr, C. 2011. Effect of a nursing information system on the quality of information processing in nursing: An evaluation study using the HIS-monitor instrument. International journal of medical informatics. 80 25-38.

[28] Mäenpää, T., Suominen, T., Asikainen, P., Maass, M., and Rostila, I. 2009. The outcomes of regional healthcare information systems in health care: a review of the research literature. International journal of medical informatics. 78 757-771.

[29] Donati, A., Gabbanelli, V., Pantanetti, S., Carletti, P., Principi, T., Marini, B., Nataloni, S., Sambo, G., and Pelaia, P. 2008. The impact of a clinical information system in an intensive care unit. Journal of clinical monitoring and computing. 22 31-36.
[30] Bosman, R. 2009. Impact of computerized information systems on workload in operating room and intensive care unit. Best Practice \& Research Clinical Anaesthesiology. 23 15-26.

[31] Chang, J., Poynton, M. R., Gassert, C. A., and Staggers, N. 2011. Nursing informatics competencies required of nurses in Taiwan. International journal of medical informatics. 80 332-340.

[32] Mahler, C., Ammenwerth, E., Wagner, A., Tautz, A., Happek, T., Hoppe, B., and Eichstädter, R. 2007. Effects of a computer-based nursing documentation system on the quality of nursing documentation. Journal of Medical Systems. 31 274-282.

[33] Wickramasinghe, N. and Goldberg, S. 2008. Critical Success Factors for Delivering M-Health Excellence. Encyclopedia of Healthcare Information Systems. 1

[34] Parker, M. E. and Smith, M. C. 2010 Nursing theories \& nursing practice. FA Davis.

[35] Hsiao, S.-J., Li, Y.-C., Chen, Y.-L., and Ko, H.-C. 2009. Critical factors for the adoption of mobile nursing information systems in Taiwan: the nursing department administrators' perspective. Journal of medical systems. 33 369-377.

[36] Ellahi, A. and Manarvi, I. 2010. Understanding Attitudes Towards Computer Use in the Police Department of Pakistan. The Electronic Journal of Information Systems in Developing Countries. 42

[37] Bernstein, M. L., McCreless, T., and Cote, M. J. 2007. Five constants of information technology adoption in healthcare. Hospital Topics. 85 17-25.

[38] Abedini, S., Takhti, H. K., and Abedini, S. 2011. Assessing nursing curriculum: Graduate nurse viewpoints. Physiology. 13 20.26.

[39] Konstantinidis, G., Anastassopoulos, G. C., Karakos, A. S., Anagnostou, E., and Danielides, V. 2012. A usercentered, object-oriented methodology for developing health information systems: a Clinical Information System (CIS) example. Journal of medical systems. 36 437-450.

[40] Zhang, H., Cocosila, M., and Archer, N. 2010. Factors of adoption of mobile information technology by homecare nurses: a technology acceptance model 2 approach. Computers Informatics Nursing. 28 49-56.

[41] Abdrbo, A. A., Hudak, C. A., Anthony, M. K., and Douglas, S. L. 2011. Information systems use, benefits, and satisfaction among Ohio RNs. Computers Informatics Nursing. 29 59-65.

[42] Huryk, L. A. 2010. Factors influencing nurses' attitudes towards healthcare information technology. Journal of Nursing Management. 18 606-612.

[43] Kaya, N. 2011. Factors affecting nurses' attitudes toward computers in healthcare. Computers Informatics Nursing. 29 121-129.

[44] Fishbein, M. and Ajzen, I. 1975 Belief, attitude, intention and behavior: An introduction to theory and research.

[45] Davis, F. D. 1989. Perceived usefulness, perceived ease of use, and user acceptance of information technology. MIS quarterly. 319-340. 
[46] Venkatesh, V., Morris, M. G., Davis, G. B., and Davis, F. D. 2003. User acceptance of information technology: Toward a unified view. MIS quarterly. 425-478.

[47] Ajzen, I. 1985 From intentions to actions: A theory of planned behavior. Springer.

[48] Taylor, S. and Todd, P. A. 1995. Understanding information technology usage: A test of competing models. Information systems research. 6 144-176.

[49] Polit, D. F. and Beck, C. T. 2006. The content validity index: are you sure you know what's being reported? Critique and recommendations. Research in Nursing and Health. 29 489-497.

[50] Polit, D. F. and Beck, C. T. 2004 Nursing research: Principles and methods. Lippincott Williams \& Wilkins.

[51] Grant, J. S. and Davis, L. L. 1997. Selection and use of content experts for instrument development. Research in nursing \& health. 20 269-274.

[52] Sittig, D. F., Hazlehurst, B. L., Palen, T., Hsu, J., Jimison, H., and Hornbrook, M. 2002. Clinical information system research agenda for kaiser permanente. Permanente J. 6

[53] Kaplan, B. and Shaw, N. 2004. Future directions in evaluation research: people, organizational, and social issues. Methods of Information in Medicine-Methodik der Information in der Medizin. 43 215-231.

[54] Baus, A. 2004. Literature review: barriers to the successful implementation of healthcare information systems. Office of Health Services Research, West Virginia University Department of Community Medicine, Morgantown, WV.

[55] Wager, K. A., Lee, F. W., White, A. W., Ward, D. M., and Ornstein, S. M. 2000. Impact of an electronic medical record system on community-based primary care practices. The Journal of the American Board of Family Practice. 13 338-348.

[56] Vafaee, A., Vahedian, M., Esmaeily, H., and Kimiafar, K. 2010. Views of users towards the quality of hospital information system in training hospitals. Journal of research in health sciences. 10 47-53.
[57] Heller, E. E. 1995. The computer-based patient record vision contrasted with HIS/MIS. International journal of bio-medical computing. 39 19-23.

[58] Abrahamsen, C. 2003. Patient safety: take the informatics challenge. Nursing management. 34 48-51.

[59] Bradley, C. 2003. Technology as a catalyst to transforming nursing care. Nursing outlook. 51 S14-S15.

[60] Pynoo, B., Devolder, P., Duyck, W., van Braak, J., Sijnave, B., and Duyck, P. 2012. Do hospital physicians' attitudes change during PACS implementation? A crosssectional acceptance study. International journal of medical informatics. 81 88-97.

[61] Ismail, N. I., Abdullah, N. H., Shamsudin, A., and Ariffin, N. A. N. 2013. Implementation differences of hospital information system (HIS) in Malaysian public hospitals. Technology. 2022.

[62] Lee, H. W., Ramayah, T., and Zakaria, N. 2012. External factors in hospital information system (HIS) adoption model: a case on malaysia. Journal of medical systems. 36 2129-2140.

[63] Lorenzi, N. M., Kouroubali, A., Detmer, D. E., and Bloomrosen, M. 2009. How to successfully select and implement electronic health records (EHR) in small ambulatory practice settings. BMC medical informatics and decision making. 915 .

[64] Khalifa, M. 2013. Barriers to health information systems and electronic medical records implementation. A field study of Saudi Arabian hospitals. Procedia Computer Science. 21 335-342.

[65] w Creswell, J. 2009 Research design: Qualitative, quantitative, and mixed methods approaches. SAGE Publications, Incorporated.

[66] Cavana, R., Delahaye, B. L., and Sekeran, U. 2001 Applied business research: Qualitative and quantitative methods. John Wiley \& Sons Australia.

[67] Zikmund, W. G. 2003. Sample designs and sampling procedures. Business research methods. 7 368-400.

[68] Ridder, H.-G. and Yin R. K. 2012. Case Study Research. Design and Methods 4 th ed. 2012, Rainer Hampp Verlag. 